\title{
Introduction: historical and emerging themes in sustainable business
}

\section{Geoffrey Wells}

\section{PRECURSORS}

It is usual to trace the historical antecedents of the idea of sustainable business to at least the 1950s. In the course of sixty years the emerging conceptual landscape of that idea has been wide-ranging. Included in it are: corporate philanthropy; corporate social responsibility (CSR); corporate social responsiveness; corporate social performance (CSP); public responsibility; business ethics; stakeholder theory; corporate citizenship; corporate social marketing and so on. These are not paradigms, in the strict sense (Kuhn 1996). Rather they are conceptual frameworks - some more formalized, some better documented than others - through which the wider responsibilities of the firm have been analyzed (Carroll 2008; Lee 2008). This historical trajectory is now briefly described, through some central contributions.

Carroll (2008) notes that from the late 1800s on, critiques of working conditions in the emerging factory system in Great Britain were successfully mounted. The courts began to wrestle with the legitimate limits of corporate philanthropy (Wren 2005). Initiatives such as the Pullman town, a model industrial community, were attempted (Heald 1970). Management theorists began to explore the relationship between corporate profitability and social responsibility: Berle and Means (1932, p. 312) examined the claims of passive owners and articulated the important principle that 'Neither the claims of ownership nor those of control can stand against the paramount interests of the community'; this was, Stretton (2000, p. 362) remarks, 'a proposal to save capitalism, not to replace it.' Similarly in an early work, Drucker (1946, p. 256) argued that there were limits to the operation of the market: '... No society can allow labor, physical resources of land or equipment and money to be treated as "commodities". The market cannot be allowed to destroy them nor to destroy their stability.' In two of these factors, labor and physical resources of land, can be seen conceptual roots of the internal and external dimensions of the sustainable firm. 
However it is widely agreed that the first codified account of the social dimensions of business was Howard R. Bowen's Social Responsibilities of the Businessman (Bowen 1953). Many of the central concepts of CSR and sustainable business theory over the succeeding six decades are prefigured here. Bowen bases his argument on a broadly conceived account of the goals of the economic system: these include not only economic progress and stability, but the wider goals of justice, freedom, the development of the individual person, community improvement and personal integrity. Such goals then become criteria according to which the social performance of business is judged. Moreover they are delivered by ethical conduct: 'Businessmen have always been expected to act according to sanctioned rules of conduct ... morality is one of the foundations of economic life' (p.13). Principled action is required; a notion expanded upon by a later generation of economists (Lutz 1999).

Bowen's position challenged a century of unfettered American business. Included in it are many concepts that have now become central to the discourse of CSR and sustainable business. Stewardship is associated with the idea that business leaders are servants of society, for whom 'management merely in the interests (narrowly defined) of stockholders is not the sole end of their duties' (Bowen 1953, p. 44), a central theme of socially responsible business (ICAEW 1975). It is taken for granted that free enterprise is the most productive economic system, and profitability (or at least 'satisfactory' profits) is the first requirement for a firm; but once secured other responsibilities to society must be considered. The directors of a firm are 'trustees, not alone for stockholders or owners, but also for workers, suppliers, consumers, the immediate community, and the general public', amongst whose interests they are required to mediate (Bowen 1953, p.48). In that task, recourse will be taken to 'ethical connotations which extend far beyond the narrow principle of profit maximization' (p. 50). This model of the firm has its foundation in community values: 'The changing values and attitudes of the public have persuaded businessmen, in a decisive way, to reconsider their social role and the aims of their activity' (p.53). It is not difficult to see in this analysis the foundations of stakeholder theory (Dunfee 2008), of business ethics (Brenkert 2010), and of the social license to operate (Kurucz et al. 2008).

Among these responsibilities of the firm, those which pertain to employees are among the most unambiguous. Bowen observes that 'the wants and needs of workers extend far beyond wages' and that management must act proactively 'in giving workers the things essential to make of work a satisfying and rewarding human experience'. Bowen's extended list of those things deemed essential present a formidable summary of what have 
become organizational dimensions of the firm in CSR and sustainable business theory (Bowie 2010).

Bowen faces the challenge this model of the firm poses to competitive business: that since some competitors will not 'accept their social responsibilities' and the costs that come with them the socially responsible firm will be uncompetitive. Bowen counters with the observation that better employment practices historically have resulted in greater productivity; an early approach to the business case for CSR (Carroll and Shabana 2010). Furthermore from an economic point of view, aggregate welfare is increased: 'The welfare of society is related not only to the quantity of final goods and services but also to the conditions under which these goods and services are produced' (p.113); a principle upon which the modern disciplines of environmental and natural resource economics (Perman et al. 2003) and ecological economics (Common and Stagl 2005) have systematically expanded. There are in any case unavoidable moral obligations, and these extend widely: to immediate moral obligations are added 'obligations that are distant and less clearly seen' (p. 123); a statement which aligns with the later sustainability principles of social justice and intergenerational equity (Rawls 1972; WCED 1987).

Davis (1960, p. 76) adopted a position not far from Bowen's: 'Clearly, economic functions of business are primary, but this does not negate the existence of non-economic functions and responsibilities. The price of social freedom is its responsible exercise.' The considerable power of business is to be balanced in a 'co-equal responsibility': the continuing vitality of business depends upon it; refusal to accept it threatens the foundations of a stable society. In practice, Davis proposes, it is a matter of determining which economic decisions also have social dimensions, and including the latter in business decision making. Those dimensions are recognized as being both internal and external to the firm, as in the conditions of work and in the implications for wider employment. Importantly Davis argues that an ethical imperative may be embedded in the firm's collective beliefs and actions, but that does not relieve the individual of the obligation to act ethically: ' $\ldots$. in the last analysis it is always the businessman who makes the decision' (p. 71).

Frederick (1960) began a long engagement with CSR theory by accepting the requirement for business to deliver 'broad social ends' and to attend properly to the welfare of its employees. However he counsels an acceptance of the profit motive, on historical and cultural grounds, and from a recognition of limits in actions open to business managers (1960). He looks rather to the public institutional context to attach appropriate social dimensions to business actions.

These themes were treated with increasing rigour in the following 
decades. Friedman's famous magazine article has been endlessly cited as presenting a fundamentalist neoclassical view of the firm entirely opposed to the idea of a sustainable enterprise (Friedman 1970). A closer reading presents a more nuanced view.

Friedman's thesis is that the sole responsibility of the corporate executive is to his employers, the owners. (This view was later challenged under ethical theory - for example, by Solomon (2004) - but let us see where Friedman takes it.) Owners will normally want 'to make as much money as possible while confirming to the basic rules of the society, both those embodied in law and those embodied in ethical custom'; an interesting constraint, often overlooked in commentary.

In the standard corporate model, then, to incur costs to the company for social purposes, such as improving the environment, is therefore not acting in the interests of the owner: it is 'spending someone else's money for a general social interest', in a different way than the owners would have spent it (unless, of course, the owners were predisposed to act in this way). This is, Friedman argues, in effect a corporate tax, and it represents a breach not of ethical but of political principle. Furthermore it is unreasonable to expect the businessman to be 'simultaneously legislator, executive and jurist' and expert in social matters such as macroeconomic policy or environmental policy.

By contrast, he argues, in standard libertarian mode, under a free market system '. . . no individual can coerce any other, all cooperation is voluntary, all parties to such cooperation benefit or they need not participate. There are no values, no "social" responsibilities in any sense other than the shared values and responsibilities of the individuals'.

Importantly it is accepted that the market mechanism is not always feasible: '. . . I do not see how one can avoid the use of the political mechanism altogether.'

It should be noted that Friedman is not arguing against social goals per se: he is arguing that firms should not and cannot (by reasons of both governance and expertise) develop or implement them. Social goals, in his view, belong to social governance: they are political and should be set by the political mechanism in legislation and regulation. The ethical elements of such goals are socially embedded; a view, ironically, that modern critical theorists such as Habermas (1990) have elaborated.

Baumol (1970) examined the long established practice of corporate philanthropy. He cites court opinions that 'corporate giving has been found appropriate so long as it serves the interests of the firm, broadly defined.' A broad business case for corporate giving is proposed: 'The company pays a high price for operating in a region where education is poor, where living conditions are deplorable, where health is poorly protected, where 
property is unsafe, and where cultural activity is all but dead.' Where that price is greater than the price of corporate giving, corporate philanthropy makes business sense. Particularly if government action is absent, such giving is seen as best handled collectively, by voluntary groupings of firms.

A similar more formal argument was mounted by Wallich and McGowan (1970). The key question, it is proposed, is the appropriability by the firm of returns on social investment. Social arenas include the quality of the environment (air, water) and social stability (equality of opportunity). The analysis points to the rationality of a corporate strategy which pursues all such returns appropriable through the market system but avoids actions which generate non-market returns. Again it is concluded that voluntary cooperation by firms (short of antitrust actions) will yield best financial results.

The plethora of positions unleashed by Friedman's article leads to a demand for greater formalization of the CSR domain. Sethi (1975) proposed a tripartite framework for corporate behaviour: social obligation, based on economic criteria; social responsibility, based on social norms, values and expectations; and social responsiveness, which demands a long term view that is both anticipatory and preventative.

Carroll's (1979) analysis of CSR has been influential over three decades. He offered a four part definition of CSR: 'The social responsibility of business encompasses the economic, legal, ethical, and discretionary expectations that society has of organizations at a given point in time' (p.500). The first two elements of this definition comprise the basic requirements the society has of business: to make a profit, and to abide by the law (the Friedmanite limit of firms' purposes). In addition, however, Carroll proposes ethical and discretionary elements which go beyond obedience to the law and are answerable to social norms. He later emphasized that, although it is attractive to categorize the first two elements as what the firm does for itself and the second two as what the firm does for others, in reality 'economic viability is something business does for society as well' (Carroll 1999, p. 284). Subsequent versions of the schema were presented as a pyramid, with economic responsibility forming its base.

Carroll (2008, p.36) notes the extension of the concept during the 1980 s to 'environmental pollution, employment discrimination, consumer abuses, employee health and safety, quality of work life, deterioration of urban life, and questionable/abusive practices of multinational corporations', a considerable expansion of scope, both internal and external to the firm. Wartick and Cochran (1985) elaborated Carroll's schema in an integrating framework of corporate social responsibilities, corporate social responsiveness and social issues under dimensions of principles, processes, and policies. 
However the dominant contribution to the field during this period came from Freeman's development of stakeholder theory (Freeman 1984; Freeman et al. 2010). Although presented in the context of strategic management, stakeholder theory had a substantial impact on the development of all fields dealing with business and society, and was developed by Freeman himself over more than two decades. Freeman observes that the legal question of corporate responsibility had moved 'to give de facto standing to the claims of groups other than stockholders. It has, in effect, required that the claims of customers, suppliers, local communities, and employees be taken into consideration' (Freeman 2009, p. 58).

$\mathrm{He}$ argues against the attempt to separate business decisions from ethical decisions and in favor of an integrated view, which recognizes the inherently ethical nature of business decisions and the obligation of businesses to accept responsibility for it. Stakeholders in the firm are 'groups and individuals who can affect or are affected by, the achievement of an organization's mission' (Freeman 1984, p.52). They include secondary entities, such as consumer groups, special interest groups, media, government, and even competitors. Freeman cites principles from various traditional and modern ethical theories in support of his position.

At this point the conceptual building blocks of theory relating to the social responsibilities of business were mostly identified, although the form of that theory was not agreed upon. The subsequent two decades saw a further expansion of scope: for example, in management, to strategic giving and social marketing; and in business practice, to community investment and governance. An emphasis on performance, particularly financial performance, drove new research programs. However it is the emergence of sustainability as a framing concept that is the most significant of these more recent developments.

Even with the expansion of scope of CSR and related fields in the 1980s, the application of sustainability principles to business has strongly challenged the adequacy of the conceptual frameworks that CSR theory had developed. The roots of sustainability thinking extend over many decades (Meadows et al. 1972, 1992, 2005). However its modern formulation is identified with the United Nations report, Our Common Future (WCED 1987). This report ranged widely over global challenges, predominantly economic and environmental, but including also poverty, inequality and militarization; population growth and food security; biodiversity and ecosystem integrity; energy, industry and urbanization; and the institutional changes needed for sustainable development. It firmly endorsed the concept of global environmental limits. As is well known, it proposed a view of sustainability which has been definitive: 'Sustainable development seeks to meet the needs and aspirations of the present without 
compromising the ability to meet those of the future' (p.40). Intragenerational equity is equally emphasized: 'A world in which poverty and inequity are endemic will always be prone to ecological and other crises' (p. 43).

Our Common Future framed the development of sustainability principles and practice for two decades. The Rio Declaration on Environment and Development (UNDESA 1999) articulated 27 principles, which are essentially a formalization of the Brundtland report. One is the precautionary principle (Principle 15). Another is the internalizing of external costs (Principle 16): 'National authorities should endeavour to promote the internalization of environmental costs and the use of economic instruments, taking into account the approach that the polluter should, in principle, bear the cost of pollution, with due regard to the public interest and without distorting international trade and investment.' The recent Rio +20 deliberations have essentially confirmed these principles.

On these readings it is evident that when applied to business, sustainability principles represent a dramatic expansion of the earlier scope of CSR and its affiliates. The responses of the academic and professional communities have varied widely. An early contribution which directly reflected the WCED analysis was Hart (1997), who proposed a context for sustainable business which required developed, emerging, and survival economies to be evaluated against the major sustainability challenges of pollution, depletion (of renewable resources), and poverty.

Montiel (2008) investigated the relationship between CSR and CS (corporate sustainability) in a quantified review of articles in selected leading journals over the period 1970-2005. The study demonstrated some expected trends: a longer history of CSR research; an increase in CS and EM (environmental management) articles since 1990; and a shift of interest from CSR to corporate social performance (CSP) after 1990. Definitions of CSR reflected the wide range of perspectives outlined above. On the other hand, CS definitions were more focused: on ecological sustainability, identifying CS primarily with the environmental dimension of business; and on the tripartite construct - environmental, economic, and social - associated with the WCED approach and its successors (Elkington 1997).

Montiel identified several points of difference emerging from the research between CSR and CS. CS treats economic, social and environmental dimensions as integrated; CSR deals only with the social and economic, and maintains their separation. CS tends to be eco-centric; CSR anthropocentric. CSR, as we have seen, has come to centre on stakeholder theory; CS has moved to resource based views, motivation theory and institutional theory. At the same time CSR has begun to incorporate 
environmental elements, such as pollution abatement and conservation of natural resources; and CS is placing increasing importance on the social dimension, in areas such as government relationships, stakeholder interests, health and safety, and community development. Montiel concluded that the two fields are converging: 'Contemporary businesses must address economic prosperity, social equity, and environmental integrity before they can lay claim to social responsible behavior or sustainable practices' (Montiel 2008, p. 260).

This conclusion was supported by Dahlsrud (2008), who conducted a review of CSR definitions in both journal articles and web pages over the period 1980-2003. Utilizing frequency scores, five dimensions of CSR were identified: environmental; social; economic; stakeholder; and voluntariness. Of these the environmental dimension is somewhat lower in frequency. Importantly Dahlsrud notes that most of the definitions are descriptive, rather than normative: rather than arguing for the social responsibility of business, they 'describe CSR as a phenomenon.' He concludes from the data that CSR 'is nothing new at a conceptual level' but is being brought into new operational focus in a globalized economy: New stakeholders and different national legislations are putting new expectations on business and altering how the social, environmental and economic impacts should be optimally balanced in decision making' (p. 6).

The general thesis of CSR/CS convergence is developed further by Dyllick and Hockerts (2002). They observe that to the themes of economic growth and social equity has now been added 'concern for the carrying capacity of natural systems.' It is proposed that none of the three can be developed on its own. Sustainability interpreted as eco-efficiency - the entry point for most firms - is judged inadequate, even on sustainability criteria. Stakeholder concepts are used to present an integrated definition: '. . corporate sustainability can accordingly be defined as meeting the needs of a firm's direct and indirect stakeholders (such as shareholders, employees, clients, pressure groups, communities, etc.), without compromising its ability to meet the needs of future stakeholders as well.'

A triple-bottom line approach is thus proposed, along with a demand to integrate short with long term perspectives and strategies. In practice sustainability is to be implemented by managing three types of capital. Economic capital includes financial, tangible and intangible components (Stewart 1999). Natural capital includes natural resources and ecosystem services (Hawken et al. 2008; Heal 2005). Social capital includes human capital (of employees and business partners) and societal capital (public services) (Putnam 2001). Sustainable enterprise requires all three types of capital to be at least maintained, and ideally increased. It is emphasized that natural capital cannot always be substituted for by economic capital, 
and is characterized by non-linear processes, thresholds and irreversibility, which support the application of the precautionary principle in practice.

\section{EMERGING THEMES OF SUSTAINABLE BUSINESS IN THIS BOOK}

The chapters in this volume come from researchers in sustainable business at one university, the University of South Australia. They reflect the wide range of themes now emerging in the international exploration of sustainability principles in management and business.

The first group of chapters focuses on the foundations of the sustainable firm and sustainable business. Sandhu addresses a principal challenge of sustainability theory, that of complexity. The focus here is the environmental and social responsiveness of firms. Sandhu argues for a more holistic view of the sustainable firm and its activities derived from cross-theoretical analysis. Stakeholder and resource dependence theories offer an account of stakeholder influence on the environmental and social responsiveness of firms. Institutional theory illuminates stakeholder legitimization and approval. The resource based perspective provides a firm-specific view of how firms may break free of institutional influences. Integrating these approaches thus points the way to a more holistic model of the drivers of corporate responsiveness to sustainability at many levels.

In the tripartite model of sustainability, the social dimension has been the least addressed. Chia examines the importance of social capital for organizational outcomes. Drawing on community research in Australia and Canada, the importance of the business organization's networks, connections and relationships with its community base is explored. Among an array of grass roots communication methods the emerging role of social media in providing a focus for connection and inclusion is emphasized. Diverse and meaningful communication establishes trust between the business organization and its community, and lays the ground for business activity that is on the one hand more competitive and on the other more socially responsible.

The ethical theme in the history of socially responsible business models was established at its inception. Wells argues for the fundamentally ethical character of conceptions of the sustainable firm: in particular, that from Kantian ethics and common morality theories can be derived the essential features of the sustainable firm and its activities. Four concepts generally regarded as central to the idea of sustainable business - stakeholders, the extension of the firm's boundaries and responsibilities, sustainable organization, and future generations - are considered as consequences 
of this ethical theory. In contrast to historical classificatory schemes, it is proposed that the higher-order principle of an ethical foundation offers a coherent basis on which the theory and practice of the sustainable firm can systematically be constructed.

The second group of chapters applies sustainability concepts to core management disciplines. As each discipline has grappled with the implications of sustainability principles the reconfiguration of theory required for a coherent account of sustainable business has been developed.

Lodhia reviews the history of this work in the accounting disciplines, from both internal (sustainability management) and external (sustainability reporting) perspectives. The intellectual tensions that have emerged in the literature - for example, between accounting and sustainability metrics of success - are a particular focus. These differences are critical to the emerging account of the sustainable firm, as in business practice the firm is largely defined by the assumptions which underpin the conceptual framework of accounting. The application of these perspectives to two contemporary developments in accounting theory and practice, carbon accounting and integrated reporting, are examined, and emergent research directions in sustainable accounting are outlined.

As climate change has moved to the forefront of the global sustainability agenda, carbon measurement, accounting and auditing have become critical to the public policy responses, particularly in emissions tax or trading regimes. Ratnatunga provides a detailed review of conceptual and professional progress in this critical arena. He notes that these carbon measurement issues are important to government in the development and implementation of economic instruments; to business entities in trading, investment and cost control; and to consumers, in the provision of information for buying decisions. Current accounting and assurance frameworks are found to be inadequate to these tasks, in part because of the non-monetary character of critical carbon elements. New costing techniques incorporating whole-of-life carbon costs in products and services, and new approaches to the provision of strategic management accounting information for investment and performance evaluation are envisaged.

The role of marketing as the consumer-facing management discipline is central to the shaping and success of sustainable business. Sharp examines the tensions that are emerging for marketers between longer term social and environmental imperatives and the immediate concerns and buying behaviour of consumers. Firms increasingly view sustainability as a competitive imperative and a strategic goal, and the development of green brands as an emerging marketing responsibility and tactic. Central principles of marketing science, such as the routinized behaviour of consumers and their split loyalty across brands, have implications for meeting this 
responsibility. Well-established principles of marketing, such as understanding the market, using messages and calls to action, ensuring visibility on the shelf and in the consumer's mind, and growing sustainable brands are all found to have valuable applications to sustainability challenges.

Shen and Benson explore the internal dimensions of sustainable business through socially responsible human resources management (SRHRM). Reviewing a large body of theoretical and empirical research, they develop a nuanced conceptual framework of CSR and SR-HRM dimensions. External dimensions of SR-HRM are distinguished from internal. It is argued that it is employee-oriented SR-HRM practice which builds employee support for socially responsible acts of the organization. Addressing the interest and needs of employees is proposed as likely to minimize negative impacts on employees of external CSR initiatives and to build support for them. Enhanced organizational performance and long term sustainability are held to be organizational outcomes of this approach.

A second analysis of internal sustainability is undertaken by Fein and Tziner in a consideration of leadership and organization under sustainability principles. Leadership is approached through the relational concept of the Leader-Member Exchange (LMX), which is embedded in an integrated organizational model of individual and organizational performance. It is argued that historical core virtues of courage, justice, temperance and wisdom directly influence the leader-follower relationship, individual performance and group performance in promoting sustainability outcomes. A research program is proposed which points to the potential relevance of other core virtues, such as humanity and transcendence, and which, through appropriate operationalization of these concepts, is open to empirical testing.

The evaluation of business risk has assumed new prominence in an era characterized by high volatility, in both the physical and business environment. Chileshe et al. apply sustainability concepts to strategic risk assessment, in the context of the construction industry. A diagnostic model, framing internal, external and competitive dimensions, is used to evaluate organizational effectiveness in sustainability initiatives. The countervailing concepts of agency (human capacities) and structure (organizational rules) offer a dynamic view of sustainability initiatives in project management. These concepts are then applied to the management of project risk of two kinds: those that derive from not meeting sustainability demands, and those that accompany action to meet those demands. A sequence of actions designed to identify and respond to these risks is then derived.

The third group of chapters examines the shape sustainability principles give to businesses, particularly small and medium sized enterprises 
(SMEs), in practice. The first two of these essays focus on family firms, which, as is well known, can make up the majority of business organizations in developed economies. Most SMEs are family companies (European Commission 2009).

Sardeshmukh proposes that family firms are well suited to sustainable entrepreneurship focused on ecological sustainability. Family firms typically display stewardship, under principles of continuity and long-term preservation. Their behaviours extend beyond financial concerns to the community and the external environment. The opportunity recognition characteristic of entrepreneurial firms is thus, in the family firm, well aligned with the emerging sustainable business sector. Family firms are more likely to reduce unsustainable inefficiencies, mitigate externalities harmful to the community, position products and services with fair pricing, and address information asymmetries on sustainability with consumers. Such strategies will benefit both the firms themselves and the community at large.

Scott-Young reports an illuminating case study of an environmentally innovative medium sized family food manufacturer. The firm is a recognized leader in integrating eco-sustainability with profitability and business growth. The case study draws on theories of sustainable business practice which identify as drivers factors of economic opportunity recognition, owner-CEO environmental values, and the presence of an innovation culture. It further examines the family business concept of socioemotional capital. The value of these factors in practice is confirmed by the study. Further the importance of the external dissemination of sustainability knowledge is recognized, a finding which extends the ecosustainability literature. Links to family values and innovation emerge as future research directions.

Further insight into real world approaches taken by SMEs in implementing sustainable business practices emerges from a study of rural firms undertaken by Sawyer and Evans. Their study of 18 firms in the retail and services sector explored attitudes, values, opportunities and barriers with respect to social and environmental initiatives. In handling a range of business challenges, including employee attraction and retention, competitiveness, customer values, financial viability and so on, sustainable practice was found to have real value. Factors such as honesty and trust, responsibility to community, workplace culture, ethical approaches to the supply chain, environmental responsibility and reputation were all found to support the development of business value.

Zuo et al. focus attention on the appraisal of corporate sustainability in the construction industry. A critique of existing measurement frameworks is undertaken, and an alternative conceptual framework proposed. 
Company and project stakeholder analysis is coupled with a longer term time horizon, and applied to both products and processes. Given the dominance of SMEs in the construction industry, the scale of firms is also taken into consideration. Project culture and knowledge, with reference to sustainability principles, products and processes, is central, as is the early and ongoing participation of stakeholders. Such a framework, it is argued, can be operationalized both to generate and to measure sustainability outcomes.

The international dimension of environmental sustainability is one of its characteristic features, a physical analogue to the global economy. The final two chapters focus on international dimensions of sustainability relevant to sustainable business.

Waye addresses international legal aspects of climate change, perhaps the preeminent global issue of our time, and one which presents formidable challenges to the global business environment. The chapter outlines features of the international legal system as it has attempted, often slowly, to respond to these challenges in the arena of international trade. An account of the relevant instruments, including the Kyoto Protocol and recent international conventions and agreements, is supported by two case studies of WTO disputes. Implications for business are explored. The specific difficulties for international legal frameworks of different methods and standards for measuring carbon footprint are then examined. Harmonization of these approaches is argued to be essential.

One of the hallmarks of sustainability thinking is its attempt to coordinate physical and social factors of human well-being. Climate change presents this challenge of coordination at the highest level. A key framework for analyzing it has been provided by economics. Shanahan examines two central economic analyses of climate change, the UK Stern Report and the Australian Garnaut Reports. It is observed that conditions differ in national economies, making generalized analysis difficult. However both reports have been instrumental in deriving from the science of climate change the physical impacts on human well-being, strategies for mitigating and adapting to it, and benefit-cost analyses of different response strategies. The chapter addresses technical criticisms of the reports and explores their business implications for firms. Both reports are seen as optimistic, grounded in the demonstrated abilities of societies to make changes, both technological and institutional, when the need for change is clearly demonstrated.

The exploration of ways in which sustainability principles apply to the theory and practice of business is no small undertaking. As the chapters in this book demonstrate, its implications run wide and deep. No discipline of management stands outside it and no business practice can ignore it. 
It requires systematic work in the development of business theory, and adaptive, emergent management in the development of business practice. Ultimately, like any new paradigm, its elaboration must be a collaborative enterprise among its intellectual leaders and its practitioners, and between them. It is, we believe, an enterprise worth entering upon, in its potential to make crucial contributions to the greater well-being of people at all levels of society across the world.

\section{REFERENCES}

Baumol, W. (1970), 'Enlightened self-interest and corporate philanthropy', in W. Baumol, R. Likert, H. Wallich and J. McGowan (eds), A New Rationale for Corporate Social Policy, New York: Committee for Economic Development.

Berle, A. and G. Means (1932), The Modern Corporation And Private Property, New York: Harcourt Brace and World Inc.

Bowen, H. (1953), Social Responsibilities of the Businessman, New York: Harper \& Brothers.

Bowie, N. (2010), 'Organizational integrity and moral climates', in G. Brenkert and T. Beauchamp (eds), The Oxford Handbook of Business Ethics, Oxford, UK: Oxford University Press.

Brenkert, G. and Beauchamp, T. (eds) (2010), The Oxford Handbook of Business Ethics, Oxford, UK: Oxford University Press.

Carroll, A. (1979), 'A three-dimensional conceptual model of corporate social performance', Academy of Management Review, 4, 497-505.

Carroll, A. (1999), 'Corporate social responsibility: evolution of a definitional construct', Business \& Society, 38 (3), 268-95.

Carroll, A. (2008), 'A history of corporate social responsibility', in A. Crane, A. McWilliams, D. Matten, J. Moon and D. Siegel (eds), The Oxford Handbook of Corporate Social Responsibility, Oxford, UK: Oxford University Press.

Carroll, A. and Shabana, K. (2010), 'The business case for corporate social responsibility: a review of concepts, research, and practice', International Journal of Management Reviews, 85-105. DOI: 10.1111/j.1468-2370.2009.00275.x

Common, M. and S. Stagl (2005), Ecological Economics: An Introduction, Cambridge, UK: Cambridge University Press.

Dahlsrud, A. (2008), 'How corporate social responsibility is defined: an analysis of 37 definitions', Corporate Social Responsibility and Environmental Management, 15, $1-13$.

Davis, K. (1960), 'Can business afford to ignore social responsibilities?', California Management Review, 2 (Spring), 70-76.

Drucker, P. (1946), The Concept of the Corporation, New Jersey: Transaction Publishers Rutgers University.

Dunfee, T. (2008), 'Stakeholder theory: managing corporate social responsibility in a multiple actor context', in A. Crane, A. McWilliams, D. Matten, J. Moon and D. Siegel (eds), The Oxford Handbook of Corporate Social Responsibility, Oxford, UK: Oxford University Press.

Dyllick, T. and K. Hockerts (2002), 'Beyond the business case for corporate sustainability', Business Strategy and the Environment, 11, 130-41. 
Elkington, J. (1997), Cannibals With Forks: The Triple Bottom Line of 21 st Century Business, Oxford: Capstone.

European Commission (2009), Final Report of the Expert Group: Overview of Family Business Relevant Issues: Research, Networks, Policy Measures and Existing Studies, Brussels, Belgium: European Commission Enterprise and Industry Directorate-General.

Frederick, W. (1960), 'The growing concern over business responsibility', California Managment Review, 2 (Summer), 54-61.

Freeman, R. (1984), Strategic Management: A Stakeholder Approach, Boston: Pitman.

Freeman, R. (2009), 'Managing for stakeholders', in T. Beauchamp, N. Bowie and D. Arnold (eds), Ethical Theory and Business, London: Pearson Education, pp. 56-68.

Freeman, R., J. Harrison, A. Wicks, B. Parmar and S. de Colle (2010), Stakeholder Theory: The State of the Art, Cambridge, UK: Cambridge University Press.

Friedman, M. (1970), 'The social responsibility of business is to increase its profits', The New York Times Magazine, 13 September, available at http://graphics8. nytimes.com/packages/pdf/business/miltonfriedman1970.pdf (accessed 22 June 2012).

Habermas, J. (1990), Moral Consciousness and Communicative Action, Cambridge, MA: The MIT Press.

Hart, S. (1997), 'Beyond greening: strategies for a sustainable world', Harvard Business Review, January-February, 68-76.

Hawken, P., A. Lovins and L. Lovins (2008), Natural Capital: Creating the Next Industrial Revolution, New York: Back Bay Books.

Heal, G. (2005), Valuing Ecosystem Services, Washington, DC: The National Academies Press.

Heald, M. (1970), The Social Responsibilities of Business: Company and Community, 1900-1960, Cleveland OH: The Press of Case Western University.

ICAEW (1975), The Corporate Report, London: Institute of Chartered Accountants of England and Wales.

Kuhn, T. (1996), The Structure of Scientific Revolutions, Chicago IL: University of Chicago Press.

Kurucz, E., B. Colbert and D. Wheeler (2008), 'The business case for corporate social responsibility', in A. Crane, A. McWilliams, D. Matten, J. Moon and D. Siegel (eds), The Oxford Handbook of Corporate Social Responsibility, Oxford, UK: Oxford University Press.

Lee, M. (2008), 'A review of the theories of corporate social responsibility: its evolutionary path and the road ahead', International Journal of Management Reviews, 10 (1), 53-73.

Lutz, M. (1999), Economics for the Common Good, Abingdon, UK: Routledge.

Meadows, D.H., D.L. Meadows and J. Randers (1992), Beyond the Limits to Growth: Global Collapse or Sustainable Future, London: Earthscan.

Meadows, D.H., D.L. Meadows and J. Randers (2005), Limits to Growth: The 30Year Update, London: Earthscan.

Meadows, D.H., D.L. Meadows, J. Randers and W. Behrens (1972), The Limits to Growth: A Report for the Club Of Rome's Project on the Predicament of Mankind, New York: Earth Island, Universe Books.

Montiel, I. (2008), 'Corporate social responsibility and corporate sustainability: separate pasts, common futures’, Organization \& Environment, 21 (3), 245-69. 
Perman, R., Y. Ma, J. McGilvray and M. Common (2003), Natural Resource and Environmental Economics, Harlow, Essex, UK: Pearson Education.

Putnam, R. (2001), Bowling Alone: The Collapse and Revival of American Community, Clearwater, FL: Touchstone Books, Simon and Schuster.

Rawls, J. (1972), A Theory of Justice, Oxford, UK: Oxford University Press.

Sethi, P. (1975), 'Dimensions of corporate social performance: an analytic framework', California Management Review, 17 (Spring), 58-64.

Solomon, R. (2004), 'Aristotle, ethics and business organizations', Organization Studies, 25 (6), 1021-43.

Stewart, T. (1999), Intellectual Capital: The New Wealth of Organizations, New York: Doubleday.

Stretton, H. (2000), Economics: A New Introduction, London: Pluto Press.

UNDESA (1999), Rio Declaration on Environment and Development, New York: United Nations Department of Economic and Social Affairs.

Wallich, H. and J. McGowan (1970), 'Stockholder interest and the corporation's role in social policy', in W. Baumol, R. Likert, H. Wallich and J. McGowan (eds), A New Rationale for Corporate Social Policy, New York: Committee for Economic Development.

Wartick, S. and P. Cochran (1985), 'The evolution of the corporate social performance model', Academy of Management Review, 10, 758-69.

WCED (1987), Our Common Future, Oxford: The World Commission on Environment and Development/ Oxford University Press.

Wren, D. (2005), The History of Management Thought, Hoboken NJ: John Wiley \& Sons Inc. 